\title{
Exploring Diversification in Fast Food Chains: A Case in Eastern Visayas, Philippines
}

\author{
Jordan Cabaguinga* \\ a Eastern Samar State University, Guiuan Campus - Philippines
}

\section{A R T I C L E I N F O}

\section{Article history:}

Received on: 07 December 2021

Revised on: 13 December 2021

Accepted on: 28 December 2021

Published on: 03 February 2022

\section{Keywords:}

Diversification

Fast-food chains

Gender inequality

Managing diversity

\begin{abstract}
A B S T R A C T
Diversification is one of the main problems faced by every organization. It is considered challenging to handle; hence it caters to diversified attitudes, personality, characteristics, cultural background, perceptions, and values. This study explored the main diversity issue in fast-food chains in Eastern Visayas, Philippines, and its management. A mixed-method research design was used in the study, utilizing a survey questionnaire and an interview guide to gather the data. The results showed that gender inequality is a widespread diversity issue in fast-food chains. A relevant, suitable, and responsive diversity program must be developed to continuously educate employees on the importance of diversity in attaining organizational success. Management commitment is necessary for managing diversity.
\end{abstract}

Copyright (C) 2021 iRAPA International Journal of Business Studies. Published by International Research and Publishing Academy - Pakistan. This is an open access article licensed under CC BY:

(https://creativecommons.org/licenses/by/4.0)

\section{Introduction}

In the contextual perspective of an organization, human resources are the most valuable assets that an organization acquires. However, this is also the most complex in the management viewpoint. Hence, each of them has its own behavioural and attitudinal pattern that is unpredictable that requires an appropriate manner of responding to every behaviour and attitude. In the complex world of the hospitality and tourism industry, several issues arise about organizational behaviour. One of these is workforce diversity, which is now one of the most challenging and compounded issues. As stipulated by Moore and Woodow (2015), globalization has almost removed national boundaries that make the labour movement easy and fast that further forced organizations to deal with people of diverse cultural backgrounds, which made the management face new challenges as a result of much-needed changes in management practices.
Diversity is defined in several aspects depending on the context one takes. For example, Kreitner and Kinichi's (2014) definition pertains to the multitude of individual distinctions and similarities among the people working in an organization. However, Thomas (2016) argued that diversity does not only pertain to age, race, and gender; instead, it includes individual differences and similarities that make all workers unique and different from other organizations. In this context, diversity is not only a synonym to workers; rather, it encompasses both similarities and differences. Therefore, in dealing with diversity, management must integrate the collective differences and similarities, and both should be determined and established.

Harold and Kumar (2012) pointed out the vital consideration on regards to diversity in an organization, wherein they speculated the importance of capturing practices that is relevant to understanding and appreciating interdependence of humanity, culture, and the natural environment, commitment to mutual respect

\footnotetext{
Guiuan Campus - Philippines

E-mail addresses: jcabaguing20@gmail.com

DOI: https:// doi.org/10.48112/iijbs.v2i1.102

Copyright (C) 2021 iRAPA International Journal of Business Studies

Published by International Research and Publishing Academy

This is an open access article licensed under CC BY

(https://creativecommons.org/licenses/by/4.0)
}

* Corresponding author: Jordan Cabaguing, Eastern Samar State University,

How to cite:

Cabaguing, J. (2021). Exploring Diversification in Fast Food Chains: A Case in Eastern Visayas, Philippines. iRAPA International Journal of Business Studies, 2(1), 07-11. https://doi.org/10.48112/iijbs.v2i1.102 
for qualities and experiences that are different from its own; and most significantly understanding that diversity includes not only ways of being but also ways of knowing, recognizing personal, cultural and institutionalized discrimination that somehow creates and sustains privileges for some, while it also makes and maintain disadvantages for others, and essentially, building alliances across differences in others for people to work together to eradicate all forms of discrimination.

With all of what diversity holds to the organization, it is essential to address the issue as to what Kogler et al. (2013) stated if not adequately addressed, it may affect the organization's effectiveness, more so, to organizational profitability and productivity. As a result, staff morale has been demoralized. The attainment of organizational goals and objectives has been hampered, to the detriment of others who work in the same diversified organization. Therefore, an organization needs to harness the core values of diversity as part of organizational culture (Ogbo, Kifordu, and Ukpere, 2014).

Diversity can be a competitive advantage if properly be managed and somehow a distinctive competence of a specific organization. According to Kretner and Kinichi (2014), this competence and advantages stem from the management to diversity, which positively affects organizational behavior and effectiveness. Effectiveness in a certain point entails doing the right thing in an organizational performance factor (Unyimadu 2015). Consequently, effective diversity management could help the organization lower its costs and improve employee attitudes. Costs are reduced for it reduces health care problems, absenteeism, and employee recruitment and training.

Furthermore, effective diversity management positively impacts sales, market share, and corporate profit. This is because workforce diversity is the mirror image of consumer diversity (Kanter, 2012). In addition, Hofstede (2013) has revealed that workforce diversity promotes creativity, creative problem solving, and productivity. This is through of sharing of diverse ideas and perspectives. Similarly, effective education, training and development, and full experience exposure, whether full or part-time, enhances exposure, training, and development would promote understanding and congenial acceptance towards the realization of the overall goals of the organization through performance (Bransford et al., 2010). Within this context, this research endeavor would focus on the common issue being undertaken by the food chain establishments in Eastern Visayas as to how its employees and the manager perceived and viewed the issue they currently experienced in their work environment. This also presents a strategic framework for the organization to consider to have a wider understanding and create a cohesive working environment for their employees and the entire organization's benefit.

\section{Material \& Methods}

This section presents the methods used in the study, including the research design, participants and ethical consideration, instrument, and data analysis. This study utilized the mixed-method techniques where quantitative and qualitative data are collected concurrently, and weighted equally (Skinner et al., 2015). In addition, it utilized the sampling procedure of the total respondents of the study. The study respondents were selected based on purposive sampling, where the researcher carefully chooses the participants considering the study's objective. The respondents are expected to furnish unique data pertinent to the study. A total of 15 employees of the different fast-food chains in Eastern Visayas participated in the study.

In gathering data, the researcher asks permission from the management of the establishment for the conduct of the survey and interview. An introductory letter stating the purpose of the study was provided to the participants. Also, before the interview, the study's objective and how the participants' responses were discussed and explained. They were not forced to participate in the study; rather, they will be given the freedom to refuse or withdraw at any time without consequences. One set of the survey questionnaire was used for quantitative data. On the other hand, the researcher develops an interview guide to collect the qualitative data about the diversity in the organization, how they handle such, and the management actions regarding issues in diversity. The instrument contains the guidelines in the conduct of the interview and how the data will be treated after. The study was conducted at Eastern Visayas Philippines, one of the country's Regions considered progressive and offering several tourism activities for tourists to experience. There are a lot of fast-food chains that were built to cater the needs of the travelers while on vacation.

Descriptive statistics such as weighted mean were used to assess the quantitative data collected for this study. On the other side, thematic analysis was used to examine the qualitative data. For descriptive analysis, the researcher used the 5-Likert scale; 4.20-5.00 most frequently observed; 3.40-4.19 more frequently observed; 2.60-3.39 frequently observed; $1.80-2.59$-less frequently observed; 1.00-1.79- not at all observed.

\section{Results \& Discussion}

This section comprehensively presents and discusses the findings of the study. It started by identifying the common diversity issues fast-food chains are being experienced, followed by how they were managed are.

\section{Result of the Survey}

First, the study aims to determine the common diversity issues of fast-food chains. 
Table 1

\begin{tabular}{cccc} 
Diversity Issues & Mean & Interpretation & Rank \\
\hline $\begin{array}{c}\text { Gender Inequality } \\
\text { Respect and } \\
\text { Acceptance }\end{array}$ & 4.68 & Most Frequently Observed & 1 \\
Cultural Differences & 3.20 & More Frequently Observed & 3 \\
Generation Gaps & 3.24 & $\begin{array}{c}\text { More Frequently } \\
\text { Observed }\end{array}$ & 7 \\
Language & 2.10 & Frequently Observed & 10 \\
Discrimination & 4.20 & $\begin{array}{c}\text { Most Frequently } \\
\text { Observed }\end{array}$ & 2 \\
Stereotyping & 3.12 & Frequently Observed & 8 \\
Sexism & 2.80 & Frequently Observed & 9 \\
Belief Acceptance & 3.50 & More Frequently & Observed \\
Ageism & 3.88 & More Frequently & Observed \\
Overall Mean & 3.47 & More frequently Observed & 5 \\
\hline
\end{tabular}

Illustrated in the table above that gender inequality is the widespread diversity issue in fast-food chains in which it gains the highest mean of 4.68, which is interpreted as most frequently observed. In addition, employees experience gender inequality

The overall mean rating is 3.47 , which is interpreted as more frequently observed. The result implies that the common diversity issue being experienced by the employees in fast-food chains is gender inequality.

\section{Result of the Interview}

Table 3

\begin{tabular}{|c|c|}
\hline Sample codes & Theme \\
\hline $\begin{array}{l}\text { "It matters how issues arising in our } \\
\text { organization are being managed. } \\
\text { Diversity is a serious issue that } \\
\text { needs to be addressed immediately." }\end{array}$ & Management in Action \\
\hline $\begin{array}{l}\text { "We as employees must be aware } \\
\text { and be educated enough how we can } \\
\text { deal with our differences among } \\
\text { employees working in the same work } \\
\text { station." }\end{array}$ & Employee-Cantered \\
\hline $\begin{array}{l}\text { "It all starts by the management } \\
\text { initiative and commitment to make } \\
\text { diversity as a strength of the } \\
\text { organization." }\end{array}$ & Leadership by commitment \\
\hline
\end{tabular}

Theme 1. Accordingly, the management does not only mean that they will focus on a certain issue of diversity as being raised as the prevailing concern in the organization. Rather, it was direly emphasized that they address diversity issues from a general perspective. Most of them are currently on its close implementation of their diversity strategy programs. These programs consider that diverse individuals will learn to fit in and become like the dominant group. They classify grouping of their employees, especially in their shifting hours, as to the same group of preference, attitudes, and similar characteristics. As of now, they are still acquiring information through the rigorous observation of their employees. They also consider doing things by setting the employees aside who has too much influence on others that may greatly impact changes in organizational culture. The management isolates them by putting them on a special project. Continuing education and training is part of the program for employees to recognize and accept their differences and, most importantly, agree that everyone and everything is open to change and limit each. Suppression is an approach done by the management of telling and reinforcing others to quit whining and complaining about the issue. Part of this is by imparting the rule of the management discretion in selecting employees who could be part of the management team. It direly injected what the organization's culture entails to convey on the program. However, despite the program implementation, employees still lack satisfaction and productivity.

Theme 2. Another aspect is that an organization should be aware that the staff are people and not numbers in the company documents (Arredondo, 2013). The efficiency and effectiveness of an organization depend on its people and how they work as a team. Strategic Organizational Goal is a method that directs an individual to a specific target and aims of achievement, which also provides different approaches to managing employee differences and likes. It is strategically important for the organization to maintain its visionary objectives as it frames employees' understanding, values, and behavior towards preserving identity, integrity, and the organizations innovativeness Kostova (2014). As added by Lind (2015), strategic organizational goals ensure that all goals provided are resources that will match the emerging situation of the organization as to identify actors that would possibly illustrate differences and ways of managing them to a variety of collaborative goals.

Diverse management practices, from leadership to human resources to management practices to production enhancement to internal and external interchange, should be integrated into every part of the company's operations as a key strategic goal. Diversity management is supported by a shift in mind set that necessitates control, information, and understanding of demographic changes in the workforce over the next few years. Tepeci (2010) argued that focusing on organizational culture drives employees' understanding of their differences and provides a behavioural pattern that enhances employee job satisfaction despite the dynamic changes and interaction between employees and the organization. A significant argument has been pointed out by the Society of Human Resource Management (2018) on regards to organizational culture in which it helps employees know how the top management wants them to respond to a certain situation in a manner that employees believe that their action and response is following the acceptable behaviour of the organization. More so, it shapes employees' perception, behaviour, and understanding notably to various cultures and differences in the organization.

Theme 3. One of the important components of diversity management is by looking towards innovation and empowerment of employees and the whole organization's operations. Dhammika (2016) emphasized that visionary leadership focuses on creating and communicating an inspiring vision among subordinates to achieve and sustain superior performance. He further argued that the visionary leadership behavior of leaders improves the organizational citizenship of employees, which empowers them to be more participative in the achievement of the organizational goals and objectives. Moreover, Breevaart 
et al. (2014) confirm the great role of visionary leaders in improving the profit and morale of the employees. It was further seconded by Jehn et al. (2014) that empowering employees is by involving them in the decision-making process resulted in a commitment to achieving organizational understanding and acceptance of diversity. Changes in thinking require a command, whereas the leadership change requires a new approach and formulates a new vision and continuous support to achieve them (Harper, 2009). Any effort to change or implement change is the source to achieve competitive advantage (Tushman \& Anderson, 2009). Therefore, leadership is the most crucial aspect, and without it, nothing would happen. The transition's success depends on the organization's management's dedication and conviction. Convinced the company needs a change strategy to better its competitive position, this conviction is transformed into effective support by articulating the vision and making it clear to all company employees.

Furthermore, as Nedler (2008) speculated, effective change requires investment in resources with respect to the effort, time, and money, since achieving change effectively requires enabling the material and human potential to support changes. Human and physical resources and training and development are critical throughout the many stages of the change process. The management's primary responsibility is to assist those affected by the change in adapting to the new environment and conditions of uncertainty. And the change is proceeding as planned.

\section{Conclusions}

Diversity is an issue that needs to be responded to by any organization as it may pose several concerns that may affect to productivity, efficiency, and effectiveness of an organization. Diversity can be a key to an organization's competitive advantage if it is properly addressed. Addressing the issue of diversity depends on how the management is committed and the employee's readiness towards acceptance and understanding. Continuous training and education among employees regarding diversity will revitalize their understanding of its importance in attaining what the organization envisioned. Good leadership skills and a combination of group knowledge will help every group to reach its peak.

Furthermore, leadership can empowers diversification and attainment of which towards values formation and behavioral modification for major individual differences affect the organization. Therefore, to have an effective and strong foundation of individual or employee in the organization, appropriate management and approaches are needed to encourage job and productivity and develop a strong relationship; they have to create a basis of trust and cooperation. And all of these matters correspond to how the management looks towards the needs of addressing the issue and its full understanding of the hazards towards the employees and the organization in general.

\section{References}

Arredondo, P. (2013), Successful diversity management initiatives: A blueprint for planning and implementation, Thousand oaks, CA, Sage
Bransford, F., Boehm, S., \& Bruch H. (2010). Age Diversity, Age Discrimination, and Performance Consequences - A Cross Organizational Study.

Breevaart, K., Bakker, A., Hetland, J., Demerouti, E., Olsen, O. K., \& Espevik, R. (2014). Daily transactional and transformational leadership and daily employee engagement. Journal of occupational and organizational psychology, 87(1), 138-157.

Dhammika K. A. S. (2016). Visionary Leadership and Organizational Commitment: The Mediating Effect of Leader-Member Exchange (LMX). Wayamba Journal of Management, 4 (1), 1-10.

Harold, J. R., \& Kumar, G. R. (2012). Motivation through the design of work: Test of a theory. Organizational Behavior and Human Performance, 16, 250-279.

Harper, S.C (2009). Leading organizational change in the 21 st century industrial management, vol. 40 no. $2, p$ 25-30

Hofstede, M., (2013). The effective management of a culturally diverse workforce in five-star multinational hotels: a case study, the Westin Dublin. http://hdl.handle.net/10788/2087 , (Accessed: November 23, 2020).

Jehn, K. A., Chatwick, C., \& Thatcher, S.M. B. (2014). To agree or not to agree: The effects of value congruence, individual demographic dissimilarity, and conflict on workgroup outcomes. International Journal of Conflict Management, 8, 287-305.

Kanter, U. (2012). Knowledge of the Firm and the Evolutionary Theory of the Multinational Corporation. Journal of International Business Studies, 4th quarter: 625- 45. H. Johnson/Michigan State University.

Kogler, M., Craschke, D., Astrid ,P., Springer, C., Van der Zee, K. Managing a culturally diverse workforce: Diversity perspectives in organizations. International Journal of the Cultural Relations 37 (2013)

Kostova, Tatiana (2014). Transnational Transfer of Strategic Organizational Practices: A Contextual Perspective. The Academy of Management. http://links.jstor.org/sici?sici=B2-S (Accessed Nov. 18, 2020)

Kreitner, J., and Kinichi, M. (2014). Cultural diversity in organizations: A study on the view and management on cultural diversity

Lind,Frida (2015). Goal diversity and resource development in an inter-organisational project. Journal of Business \& Industrial Marketing, Vol. 30 Issue: $\quad 3 / 4$, pp.259-268, https://doi.org/10.1108/JBIM-11-2012-0221 (Accessed Nov. 15, 2020)

Moore, C. W., \& Woodrow, P. J. (2015). Handbook of global and multicultural negotiation. John Wiley \& Sons.

Nedler D.A. (2008), Organizational form bending principles for managing reorientation. The Academy of Managing Executives.

Ogbo, A., Kifordu, A.A., Ukpere, W.I. (2014). The effect of Workforce Diversiy in organizational Peformance of Selected Firms in Nigeria. Mediterranean Journal of Social Sciences.

Society of Human Resource Management (2018). Understanding and Developing Organizational Culture.

https://www.shrm.org/resourcesandtools/tools-andsamples/toolkits / pages/understandinganddeveloping organizationalculture.aspx (Accessed October 28, 2020). 
Tepeci, Mustafa (2010). The effect of personal values, organizational culture and person-organization, for an individual outcome in restaurant industry. Research gate Publication.

Thomas, R.R. (2016). Redefining Diversity. New York: AMACOM. https://books.google.com.ph/books? (Accessed Nov. 15, 2020)/

Tushman M.L. and Anderson (2009), Management strategic innovation and change, Oxford University Press New York, NY https://books.google.com.ph/books? (Accessed Nov. 12, 2020)

Unyimadu, M. N. (2015). Workplace diversity management effects on implementation of human resource management practices in the Ministry of Health, Kenya. 